\title{
Governance and Purchasing Function under Social Health Insurance in Nepal: Looking Back and Moving Forward
}

\author{
Vishnu Prasad Sapkota ${ }^{1}$, Umesh Prasad Bhusal ${ }^{2}$ \\ ${ }^{1}$ Insitute for Nepal Environment and Health System Development, New Baneshwor, Kathmandu, ${ }^{2}$ Save \\ the Children Nepal, Kathmandu, Nepal.
}

\begin{abstract}
Nepal is pursuing Social Health Insurance as a way of mobilizing revenues to achieve Universal Health Coverage. The Social Health Insurance governance encourages service providers to maintain quality and efficiency in services provision by practicing strategic purchasing. Social Health Security Programme is a social protection program which aspires to achieve the goals of Social Health Insurance. Social Health Security Development Committee needs to consider following experiences to function as a strategic purchaser. The Social Health Security Development Committee need to be an independent body instead of falling under Ministry of Health. Similarly, purchasing of health services needs to be made strategic, i.e., Social Health Security Development Committee should use its financial power to guide the provider behavior that will eventually contribute to achieving the goals of quality and efficiency in service provision. The other social health security funds should be merged with Social Health Security Development Committee and develop a single national fund. Finally, the state has to regulate and monitor the performance of the SHI agency.

Keywords: Design; global experiences; Nepal; purchaser; Social Health Insurance; Social Health Security Programme.
\end{abstract}

\section{INTRODUCTION}

Nepal is pursuing Social Health Insurance (SHI) as a way of mobilizing revenues to achieve Universal Health Coverage (UHC) as integrated within broader National Health Sector Strategy 2015 and Sustainable Development Goals. ${ }^{1}$ It is, therefore, high time that policy makers decide on a few challenging but important decisions. Such decisions include composition of financial contribution from poor and non-poor, benefits package, fiscal capacity to cover the benefits; SHI governance, and quality and efficiency of the delivery system while designing and implementing such a financing mechanism. ${ }^{2}$ In this paper, our purpose is to discuss the global experiences and best practices regarding the $\mathrm{SHI}$ governance which can be useful in designing SHI, which is in the inception stage in Nepal.

The SHI arrangement is designed to represent the interests of the insured. It encourages service providers to maintain quality and efficiency in services provision, which is achieved by shifting some power from the supply side to the demand side and eliminating the problems of information asymmetry between consumer and provider, the essential role of SHI governing agency/ purchaser (Figure 1). ${ }^{3}$ To facilitate such a role of the purchaser, several issues have to be addressed such as ownership of the SHI agency; organizational structure; purchasing services; and government supervision. ${ }^{4}$ Having appropriately addressed these issues, the SHI agency can act as the strategic purchaser on behalf of population. ${ }^{4}$

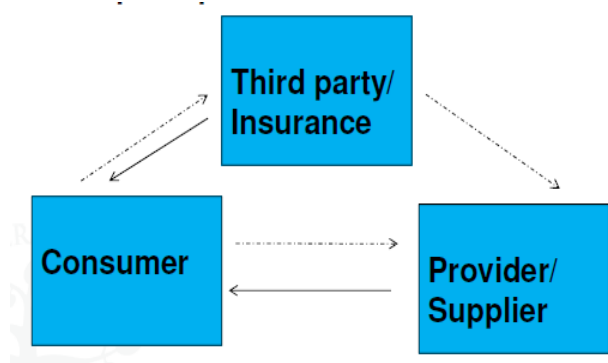

Flows:

Goods

.... Money

Correspondence: Vishnu Prasad Sapkota, Institute for Nepal Environment and Health System Development, New Baneshwor, Kathmandu, Nepal. Email: visapkota@gmail.com, Phone no: +9779841811611. 


\section{SOCIAL HEALTH INSURANCE IN NEPAL}

The Social Health Security Programme (SHSP) is a social protection program of Nepal Government which aspires to achieve the goals of SHI. The program is designed and implemented by Social Health Security Development Committee (SHSDC) and is chaired by the secretary of the Ministry of Health. The committee also includes representatives from the Ministry of Finance, Department of Health Services and subject experts. The major roles of SHSDC are policy decisions on benefit package, contribution amount, subsidies to the poor, and providers (public and private) payment mechanisms. ${ }^{5}$

\section{GLOBAL EXPERIENCES}

Global experiences regarding governance structure of the purchaser have given valuable lessons. For example, Colombia and the Philippines have established their purchaser under the Ministry of Health without representation from the premium payers. ${ }^{6}$ In the Philippines, PhilHealth was created by merging multiple purchasers into a single pooled fund (strategic purchaser). ${ }^{6}$ The secretary of the Department of Health (equivalent to Ministry of Health) is the chair of the PhilHealth board. ${ }^{6}$ Similarly, in Columbia, the National Council for Social Security in Health, chaired by the minister for social protection, is a regulatory and policymaking authority to deliver SHI. In such case, the Ministry of Health, dominated by medical professionals, tend to protect supply-side interests, and as a consequence, much of the new revenues was channelled to increasing the salaries and profits of health care providers. ${ }^{7}$ Therefore, the lesson learned from such experiences is that the purchaser needs to be an independent body (not led by the ministry of health) and free from political interference.

Further, the experiences from Philippines and Thailand provide contrasting examples of purchasing modality. The purchaser in the Philippines is a traditional, passive, and private insurance company, and acts just as a financial intermediary without using its financial power to guide the behavior of service provider. ${ }^{6}$ As a result, the pooled fund is used to benefit suppliers instead of the insured. ${ }^{7}$ In contrast, the National Health Security Office (NHSO) in Thailand adapted provider payment mechanisms (for example capitation rate) that discourage overuse of services by the consumer and guide the provider behaviour. ${ }^{8}$ Therefore, the lesson learned from such experiences is that the SHI agency should be a prudent purchaser of health services and use its financial power to guide the provider behavior.

Literature shows countries that have multiple funds and purchasers (Germany, Korea, and Taiwan) are experiencing inefficiency in service provision, and are struggling to convert the multiple $\mathrm{SHI}$ funds into a single one. ${ }^{7}$ Countries (Colombia, Ghana, Kenya, and the Philippines) learned the lesson from nations mentioned above and had established a single SHI fund from the very beginning. ${ }^{7}$ In addition, Thailand is currently engaging in an exercise to convert its multiple SHI funds into a single fund. ${ }^{8}$ Therefore, the lesson learned from such experiences is that a single pooled fund (and the purchaser) is preferable to many funds.

\section{CONCLUSIONS}

Having had such vivid experiences of designing and implementing $\mathrm{SHI}$ governance by various countries, SHSDC needs to consider following experiences. First, the SHSDC need to be an independent body instead of falling under Ministry of Health. This reformulation will empower the committee to better serve in the interest of the consumer. Similarly, purchasing of health services needs to be made strategic, i.e., SHSDC should use its financial power to guide the provider behavior that will eventually contribute achieving the goals of quality and efficiency in service provision. The other social health security funds should be merged with SHSDC and develop a single national pooled fund for purchasing services that will cover both formal and informal population. Finally, the state has to regulate and monitor the operations and performance of the $\mathrm{SHI}$ agency to assure that SHI serves the interest of society and public resources are used efficiently and prudently.

\section{REFERENCES}

1. MoHP. Nepal Health Sector Strategy (2015 - 2020). Kathmandu: Ministry of Health and Population; 2015. [Full Text]

2. Hsiao WC, Shaw RP. Social Health Insurance for Developing Nations. Washington, D. C.: The International Bank for Reconstruction and Development / The World Bank;2007.[Full Text]

3. Normand C, Weber A. Social health insurance: a guidebook for planning. Geneva: World Health Organization; 1994. [Full Text]

4. Hsiao WC, Shaw RP. Introduction, Context, and Theory: Social Health Insurance. In: Social Health Insurance for Developing Nations [Internet]. Washington, D. C.: The International Bank for Reconstruction and Development / The World Bank; 2007. p. 4-18.[Full Text] 
5. SHSHC. Social Health Security Programme: Standard Operating Procedures 2016. In: Committee SHSD, editor. Kathmandu: Social Health Security Development Committee; 2016.[Full Text]

6. Matthew J, William CH. The Philippines: Extending Coverage beyond the Formal Sector. Social Health Insurance for Developing Nations. Washington, D. C.: The International Bank for Reconstruction and Development / The World Bank; 2007.[Full Text]

7. William CH, Shaw RP. Lessons Learned and Policy Implications: SHI. In: Hsiao WC, Shaw RP, editors. Social
Health Insurance for Developing Nations. Washington, D. C.: The International Bank for Reconstruction and Development / The World Bank; 2007.[Full Text]

8. Piya H, William $\mathrm{CH}$. Thailand: Achieving Universal Coverage with Social Health Insurance. In: Hsiao WC, Shaw RP, editors. Social Health Insurance for Developing Nations. Washington, D. C.: The International Bank for Reconstruction and Development / The World Bank; 2007.[Full Text] 